\title{
Objection to a Simplified Ontological Argument
}

\section{GRAHAM OPPY}

Anselm: $\quad$ According to you, something than which nothing greater can be conceived, by having only mediated causal powers, is something than which a greater can be conceived. By contradicting yourself in this way, you have offered an indirect proof, that is, a reductio ad absurdum, that God, i.e. something than which nothing greater can be conceived, actually exists. ${ }^{1}$

Fool: $\quad$ There is no contradiction in what I said.

Anselm: $\quad$ You are, indeed, a fool!

Fool: $\quad$ Hear me out! You began by supposing that there is a distinction between having only mediated causal powers and having unmediated causal powers. You said: Pegasus has no unmediated causal powers, but has mediated causal powers through the thoughts, depictions and literature in which he figures. In contrast, those people who think about Pegasus, portray him in paintings and sculptures, and write stories about him themselves have unmediated causal powers.

Anselm: $\quad$ Yes, I did say this. ${ }^{2}$

Fool: But what is Pegasus? Do you deny that Pegasus is a flying horse?

Anselm: $\quad$ No. I agree that Pegasus is a flying horse. After all, that is what the stories say.

Fool: $\quad$ But surely flying is a causal power! How can Pegasus both be a flying horse, and yet not have any unmediated causal powers? Have you not just contradicted yourself?

Anselm: $\quad$ Perhaps I was too hasty in agreeing that Pegasus is a flying horse. Maybe what I should have said is that it is only according to the stories that Pegasus is a flying horse. After all, Pegasus does not exist: there are not, and never have been, any flying horses.

Fool: $\quad$ Still, in saying this, you do not deny that you can conceive of Pegasus - and, that when you conceive of Pegasus, you certainly conceive of Pegasus as a flying horse?

Anselm: $\quad$ No, I agree that I conceive of Pegasus as a flying horse. And from within the scope of pretence that Pegasus exists, I can say, quite correctly, that Pegasus flies.

\footnotetext{
${ }^{1}$ This is the final paragraph of Matthews and Baker (2010).

${ }^{2}$ Strictly, it is Matthews and Baker who say this. But it is clear that they mean to attribute these claims to Anselm (for the purposes of their dialogue).
} 
Fool: $\quad$ So, from one point of view — pretending that Pegasus exists — you say that Pegasus has unmediated causal powers (because, from this standpoint, you say that Pegasus flies, and flying is an unmediated causal power). But, from another point of view - taking account of the fact that there are no flying horses-you say that Pegasus has only mediated causal powers (because the only relevant causal powers belong to thoughts about, and depictions of, Pegasus).

Anselm: $\quad$ Yes, I do say both of these things.

Fool: $\quad$ And, in saying these things, you do not contradict yourself?

Anselm: $\quad$ No, there is no contradiction in what I say about Pegasus.

Fool: $\quad$ But, then, surely there is no contradiction in what I say about God, i.e. about that than which no greater can be conceived. On the one hand, pretending that God exists, I say that God has unmediated causal powers (because, from the standpoint of that pretence, God has maximal unmediated causal power). But, on the other hand, taking account of the fact - as I see it - that there is no God, I say that God can only have mediated causal powers (because the only relevant causal powers belong to the thoughts about, and depictions of, God). What looks like an argument of elegant simplicity turns out to be no argument at all.

SOPHIS

Monash University Clayton Campus Wellington Road Clayton Vic 3800

AUSTRALIA

Graham.Oppy@monash.edu

\section{References}

Matthews, G. and L. R. Baker 2010. The Ontological Argument Simplified. Analysis 70: 210-12. 